\title{
Decision Making Using DEMATEL: Avoid the Big Mistake
}

\author{
A.S.M.Touhidul Islam and Shariman Bin Mustafa \\ Faculty of Industrial Management, Universiti Malaysia Pahang, Lebuhraya Tun Razak, 26300 Gambang, Pahang, Malaysia
}

\section{ARTICLE INFO}

Article history

RECEIVED: 02-Sep-19

REVISED: 02-Oct-19

ACCEPTED: 04-Dec-19

PUBLISHED: $16-$ Dec-19

*Corresponding Author:

Email: asm touhidul_islam@yahoo.com

\begin{abstract}
Multi Criteria Decision Making, a quite common task in operation management, uses Decision Making Trial and Evaluation Laboratory method widely to identify causal relationships among factors and to draw attention to valuable insights. The scope of this method has reached the manufacturing industry, social activities, farming, financial system, environmental science, energy, and other areas, and has solved numerous practical problems. But the author has found that the results are significantly misleading as and when it is applied with global (or overall) consideration or even elements/category of unequal weights. To show the serious differences in the results misguiding decision makers, an example has been demonstrated in this study. Some previous studies are also presented in this regard. In any case, the result of the Decision Making Trial and Evaluation Laboratory from global calculation and analysis can be corrected if performed based on distinct elements (cluster wise) separately. Grading success or failure factors as per distinct elements of a system and integrating them as per criticality found at the element level, is an added methodology to the existing knowledge of using Decision Making Trial and Evaluation Laboratory. This new approach will help to decide critical factors in a truly holistic way and implement any principles, policies, or system more confidently.
\end{abstract}

Keywords: DEMATEL method; decision making; multi criteria; critical factor

\section{Introduction}

Studying social science topics usually depends on statistics as a major analytical tool and seeks to generalize from sample data collected from a population. The fundamental assumptions of the statistical approach, such as the assumed probabilistic distributions of data sets and the independence of variables, are unrealistic and unsuitable for certain real-world problems with complex and interrelated variables, attributes, and criteria (Liou \& Tzeng, 2012). Here comes the Multi Criteria Decision Making (MCDM) study which is aimed at solving a predefined problem; therefore, more emphasis is placed on constructing models that may be close to the preference of the decision maker (DM), and yield ideal or satisfactory guidance for decisions. In statistical methods and models, such as regressions, the effect of random errors is assumed to be generated independently from a normal distribution with zero mean and a specific variation. But the assumption for the probabilistic distribution of the effect of random errors is neither identifiable nor examinable (Berk \& Freeman, 2003); however, it has certain effects on the obtained regression model (Tzeng \& Shen, 2017). Hence researchers prefer the MCDM method to solve practical problems.

Also, a research project based on statistics attempts to generalize its models to support its hypotheses and theories; consequently, such projects must collect data samples that are sufficiently large to be representative for the assumed population, which can only provide averaged numbers (Spronk et al., 2005) from the sample data. Such 
averaged results can describe or explain the relationships among the explanatory and response variables. By contrast, MCDM studies often address a predefined case in which DMs attempt to select the optimal decision (ranking or resource allocation). The MCDM approach also avoids questionable probabilistic assumptions and seeks to solve problems. Again, the statistical approach tends to collect questionnaires from all available employees or shareholders to determine the average opinion; but the MCDM approach would query the preferences, knowledge, and experience of the managers of the company to devise an optimal strategy. Thus, the statistical approach puts more emphasis on examining the relationships among the variables for theoretical purposes, whereas the MCDM approach focuses on supporting DMs who must solve complicated decision problems in practice (Tzeng \& Shen, 2017). Hence for the study of ranking success factors, enablers, or barriers based on experts' judgment, MCDM is preferable to statistical analysis tools and models.

Following Omrani et al. (2019), MCDM problems can be categorized into two subfields: "Multiple Attribute Decision-making" (MADM) and "Multiple Objective Decision-making" (MODM). MADM is concerned with ranking or selecting by weighing up predetermined alternatives, and MODM is aimed at identifying the most favourable outcome by searching for a competent frontier within a solution space under the given constraints. Most conventional MCDM research comprises these two subfields of MADM and MODM (Köksalan et al., 2011). MADM methods are mainly devised for evaluations. By contrast, MODM is more suitable for designing or planning by optimizing the allocation of limited resources.

While discussing multi criteria problems, Sivakumar et al. (2018) stated that criteria interaction is principally of two categories, namely, "criteria dependency and criteria interactivity". Again, criteria dependency is subdivided into three types, namely, "structural dependency, causal dependency, and preferential dependency". In causal dependency, cause and effect relationships among factors are identified, and the statistical results are drawn (Sivakumar et al., 2018). Gölcük \& Baykasoğlu (2016) mentioned seven key techniques to find causal dependency: "Causal maps" (Rodrigues et al., 2017), "Decision Making Trial and Evaluation Laboratory" (DEMATEL) (Wu \& Lee, 2007; Patil \& Kant, 2013), "Fuzzy cognitive maps" (Salmeron et al., 2012; Ferreira et al., 2017), "Bayesian networks" (Zeng et al., 2016; Marvin et al., 2017), "System dynamics" (Xu \& Coors, 2012), "Interpretive Structural Modeling" (ISM) (Purohit et al., 2016; Girubha et al., 2016;
Agi \& Nishant, 2017) and "Structural equation modeling" (SEM) (Bagozzi, 2010; Hair et al., 2012).

The DEMATEL method was developed in Switzerland in the seventies of the twentieth century by E. Fontel and A. Gabus. The idea of the creators (Gabus \& Fontela, 1973) was for it to serve as a tool that would make it possible to solve complex problems and analyze a variety of causal links. The DEMATEL method is being used increasingly to solve various social, economic, or technical problems. A crucial assumption of this method is the comparison of objects in pairs. These objects are usually the considered factors, variants of a decision, or event. When making comparisons, the interaction between the objects being compared should be kept in mind. After considering the set of relations that exist between the compared objects, it is possible to build a graph of direct impact that illustrates these relations and is easy to interpret (Gołąbeska, 2018).

Causal maps demonstrate causal relationships of different factors using positive or negative loading of potency indicated with numbers ranging from zero to five (Rodrigues et al., 2017). The DEMATEL method identifies net causes and net effects; forms the inter-relationship map (IRM) among factors based on threshold value; and finally, provides a structural framework for the system (Wu \& Lee, 2007). Combining cognitive mapping with fuzzy logic, the fuzzy cognitive map is created (Salmeron et al., 2012) which represents the given system graphically. Bayesian networks also generate graphical models to represent information related to an undecided domain (Zeng et al., 2016). ISM is applied to identify relationships between factors and define problems clearly (Purohit et al., 2016). "System dynamics" defines problems dynamically presenting different stages of modeling and mapping ( $\mathrm{Xu}$ \& Coors, 2012), and guides to understand multifaceted problems while SEM also defines the structural relationship among factors but to provide statistical results (Bagozzi, 2010). All these methods have some strengths and weaknesses but the DEMATEL methodology is more popular for the following reasons:

i. Relatively, it is not so inflexible (Bouzon et al., 2018).

ii. Unlike ISM, it allows broad variations in relationships among factors (Yang \& John, 2003; Zhu et al., 2011; Bai \& Sarkis, 2013; Bouzon et al., 2018).

iii. To compare with "Analytic hierarchy process" (AHP), Zhu et al. (2011) stated that "DEMATEL provides multiple directional relationships, while AHP has only a unidirectional relationship and multiple separate 
matrices requiring integration" (Sivakumar et al., 2018).

iv. In comparison to the fuzzy set and probability theories, the most important benefit of DEMATEL method is its lesser requirement of sample data and higher flexibility in pattern recognition (Yang \& John, 2003).

$\checkmark$ Another key advantage of DEMATEL over other systems is its confidence on its ability to produce possible results with least amount of data (Bouzon et al., 2018).

vi The matrices portray contextual associations among system elements, where the numbers represent the strength of influences (Bouzon et al., 2018).

\section{Problem Statement}

"Most decision-making methods assume interdependence between the criteria of a decision and the alternatives of that decision, or simply among the criteria or among the alternatives themselves. However, assuming interdependence among criteria/variables is too strict to overcome the problem of dependent criteria, therefore, some papers have discussed ways to overcome this problem. The DEMATEL method is used to detect complex relationships and build the IRM of relations among criteria. The methodology can confirm interdependence among variables/criteria and restrict the relations that reflect characteristics within an essential systemic and developmental trend" (Yang et al., 2008).

But the problem in DEMATEL may arise when some factors, under a categorical element of a system like lean manufacturing, sustainable supply chain etc., do not appear influencing other factors higher and these less influential factors are omitted as non-critical. To ensure the system works properly or is even implemented effectively in the first place, all elements need to be well set in place. Especially, if the element is a distinct integral part of the system, it needs to be ensured to establish, hence the factors related to that specific element requires pair wise comparison for critical. Otherwise, the system is not completely addressed and subsequently, may fail as a whole. Commonly, impact relations of some factors may not be in the higher rank in overall implementation but for a specific element of a specific principle they can be highly influential. Therefore, segregating factors as per elements of a management system; analysing and identifying critical factors for all the elements separately; and then compiling them as per criticality found at the element level, is required to add to the existing knowledge of DEMATEL methodology.

\section{Dematel Method}

DEMATEL method was initially developed in 1970s in the "Science and Human Affairs Program of the Battelle Memorial Institute of Geneva" to study the intricate and intertwined problematic group. It has been extensively acknowledged as one of the best tools to solve the cause and effect relationships among the evaluation criteria (Wu et al., 2015; Kusi-Sarpong et al., 2016; Dong et al., 2016; Gan \& Luo, 2017; Gołąbeska, 2018; Sivakumar et al., 2018; Moktadir et al., 2018; Mangla et al., 2018) for its substantial benefits (Zhu et al., 2011; Bai \& Sarkis, 2013; Bouzon et al., 2018) over other multi criteria decision making methods. The procedure (Yu \& Tseng, 2006; Liou et al., 2007; Tzeng et al., 2007; Wu \& Lee, 2007; Yang, et al., 2008; Shieh et al., 2010) of DEMATEL method is presented below in Figure 1.

Step 1: "Calculate the initial average matrix by scores. In this step, respondents are asked to indicate the degree of direct influence each factor/element i exerts on each factor/element $j$, which is denoted by $A_{i j}$. We assume that the scales $0,1,2,3$ and 4 represent the range from no influence to very high influence. Each respondent would produce a direct matrix and an average matrix" (Yang et al., 2008). For each expert, an nxn non-negative matrix is constructed as $X^{k}=X^{k}{ }_{i j}$, where $k$ is the expert number of participating in evaluation process with $1 \leq k \leq m$. Thus, $X^{1}, X^{2}, X, \ldots, X^{m}$ are the matrices from $m$ experts (Liu et al., 2011; Sumrit \& Anuntavoranich, 2013). To aggregate all judgments from $m$ experts, the average matrix $Z=\left[z_{i j}\right]$ is shown below (Sumrit \& Anuntavoranich, 2013).

$Z_{i j}=(1 / m) \sum_{i=1}^{m} x_{i j}^{k}$

Equation [1]

Step 2: The "normalized initial direct-relation matrix" (Wu \& Chang, 2015) $D=\left[d_{i j}\right]$, where the matrix value is ranged between $[0,1]$. The calculation is shown below (Yang et al., 2008; Sumrit \& Anuntavoranich, 2013):

$D=\lambda^{*} Z$

Equation [2]

Where $\lambda=\operatorname{Min}\left[1 /(\max 1 \leq i \leq n) \sum_{i=1}^{n}\left|Z_{i j}\right|, 1 /(\max 1 \leq i \leq n) \sum_{j=1}^{n}\left|Z_{i j}\right|\right]$

Step 3: The "total-influence matrix $T$ " is obtained by utilizing Equation 3, in which, "I is an $n \times n$ identity matrix". The indirect effects of factor $i$ on factor $j$ are represented by The element of $t_{i j}$, then the total relationship between 


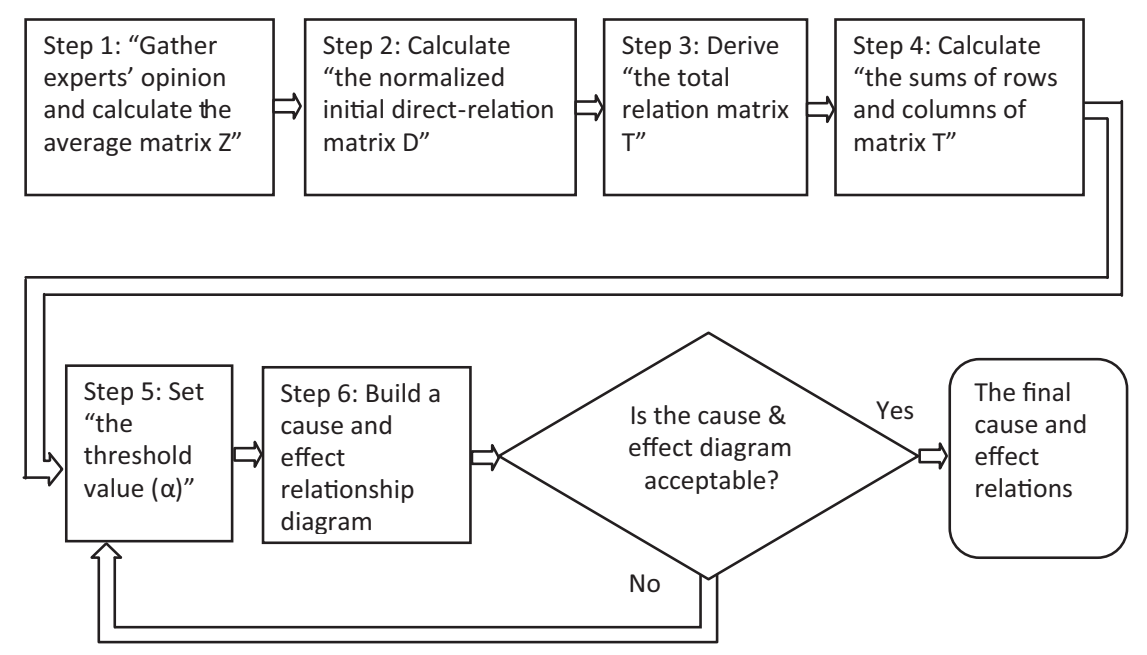

Figure 1: DEMATEL Analysis Flow Diagram

Source: Sumrit \& Anuntavoranich (2013)

each pair of system factors is reflected in the matrix T (Liu et al., 2011; Sumrit \& Anuntavoranich, 2013).

$$
T=D(I-D)^{-1}
$$

Equation [3]

Step 4: In matrix $T$, the vectors $r$ and $c$ represent the sum of rows and the sum of columns, respectively:

$r=\left[r_{i}\right]_{n \times 1}=\left(\sum_{i=1}^{n} t_{i j}\right)_{n \times 1}$

Equation [4]

$c=\left[c_{j}\right]_{1 \times n}^{\prime}=\left[\sum_{j=1}^{n} t_{i j}\right]_{1 \times n}^{\prime}$

Equation [5]

" $\left[c_{j}\right]$ ' is transposition matrix" (Liu et al., 2011; Sumrit \& Anuntavoranich, 2013).

"Where $r_{i}$ denotes the row sum of the $i^{\text {th }}$ row of matrix $T$ and shows the sum of direct and indirect effects of factor/element $\mathrm{i}$ on the other factors/elements. Similarly, $c_{j}$ denotes the column sum of the jth column of matrix $T$ and shows the sum of direct and indirect effects that factor/element $\mathrm{j}$ has received from the other factors/ criteria. In addition, when $i=j$ (i.e., the sum of the row and column aggregates) $\left(r_{i}+c_{i}\right)$ provides an index of the strength of influences given and received, that is, $\left(r_{i}+c_{i}\right)$ shows the degree of the central role that factor i plays in the problem" (Yang et al., 2008). "In contrast, the difference $\left(r_{i}-c_{i}\right)$ represents the net effect that factor i contributes to the system. Specifically, if $\left(r_{i}-c_{i}\right)$ is positive, factor $\mathrm{i}$ is a net cause, while factor $\mathrm{i}$ is a net receiver or result if $\left(r_{i}-c_{i}\right)$ is negative" (Wu \& Chang, 2015).

Step 5: "Set a threshold value and obtain the IRM. Setting a threshold value $\alpha$, to filter the minor effects denoted by the factors of matrix $T$ is necessary to isolate the relation structure of the factors. Based on the matrix $T$, each factor $t_{i j}$ of matrix $T$ provides information about how

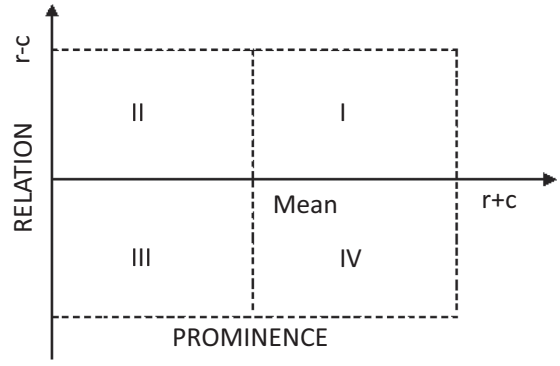

Figure 2: Four quadrants IRM structure Source: Si et al., 2018

factor $\mathrm{i}$ affects factor $\mathrm{j}$. In practice, if all the information from matrix T converts to the IRM, the map would be too complex to show the necessary information for decision making. In order to reduce the complexity of the IRM, the decision-maker sets a threshold value for the influence level: only factors whose influence value in matrix $T$ is higher than the threshold value can be chosen and converted into the IRM. The threshold value can be decided through the brainstorming of experts. When the threshold value and relative IRM have been decided, the IRM can be shown" (Yang et al., 2008).

Many researchers (Chuang et al., 2013; Chien et al., 2014; Si et al., 2018) have divided the IRM into four quadrants (Figure 2), by calculating the mean of $r+c$. As $r+c$ represents prominence and $r$-c represents relation, "The factors in quadrant $I$ are identified as core factors or intertwined givers since they have high prominence and relation; the factors in quadrant II are identified as driving factors or autonomous givers because they have low prominence but high relation. The factors in quadrant III have low prominence and relation and are relatively disconnected from the system (called independent factors or autonomous receivers); the factors in quadrant 
IV have high prominence but low relation (called impact factors or intertwined receivers), which are impacted by other factors and cannot be directly improved. From Figure 2, decision makers can visually detect the complex causal relationships among factors and further spotlight valuable insights for decision making" (Si et al., 2018).

\section{Calculation and Analysis}

Let us assume, Z matrix by applying Equation 1 for experts' scores of success factors to remain healthy like eating habit (F1), physical exercise (F2), sleeping order (F3), physical check-up (F4), social interaction (F5), moral consciousness (F6), sense of purpose (F8), financial solvency (F8) and community (F9) is in Table 1 below:

Then, following Equation 2 and 3 the researchers can get the T matrix; and Equation 4 and 5 for corresponding ' $r+c$ ' \& ' $r-c$ ' for factors of health as shown in Table 2 given below:

Considering, health has two distinct components of physical health $(\mathrm{PH})$ and mental health $(\mathrm{MH})$; success factors
$F 1, F 2, F 3, F 4, F 5$ and F6 have effects on PH and F4, F5, F6, F7, F8 and F9 influence $\mathrm{MH}$; if the same steps are followed with the equations, the T matrix, and ' $r+c$ ' \& ' $r-c$ ' values for $\mathrm{PH}$ and $\mathrm{MH}$ are shown in Table 3 and Table 4:

Finally, following step 5, three IRMs can be drawn as given in Figure 3 below:

\section{Results and Discussion}

If the global (or overall) IMR is followed, the factors F5 and $\mathrm{F} 7$ are the most critical factors; also factor F4 can be considered as it is very close to average $r+c$ value. But the IRMs of components $\mathrm{PH}$ and $\mathrm{MH}$ are showing that in addition to factors F4, F5 and F7; factor F2 is very critical for $\mathrm{PH}$ and subsequently for health as we can not ignore $\mathrm{PH}$. To be perfectly decided, the factors F6 from IRM of $\mathrm{PH}$ and $\mathrm{F} 8$ from IRM of $\mathrm{MH}$ should be considered as quite critical; but in IRM of health, although factors F8 and F9 are in Q2 and far from the average $\mathrm{r}+\mathrm{c}$; factor $\mathrm{F} 6$ is in Q3 which is quite deceiving. Thus it is proved that to get reliable results from DEMATEL, factors need to be evaluated separately/independently for each part or element of the

Table 1: Z Matrix for Factors of Health

\begin{tabular}{|c|c|c|c|c|c|c|c|c|c|}
\hline & F1 & F2 & F3 & F4 & F5 & F6 & F7 & F8 & F9 \\
\hline F1 & 0.0 & 0.0 & 3.0 & 0.0 & 1.0 & 0.0 & 1.0 & 0.0 & 0.0 \\
\hline F2 & 3.0 & 0.0 & 4.0 & 0.0 & 1.0 & 1.0 & 0.5 & 0.5 & 0.2 \\
\hline F3 & 3.0 & 2.0 & 0.0 & 0.0 & 2.0 & 1.0 & 0.0 & 0.5 & 0.0 \\
\hline F4 & 3.0 & 3.0 & 4.0 & 0.0 & 0.0 & 4.0 & 0.5 & 0.2 & 2.0 \\
\hline F5 & 0.0 & 0.0 & 1.0 & 1.0 & 0.0 & 0.0 & 3.0 & 3.0 & 3.0 \\
\hline F6 & 3.0 & 3.0 & 2.0 & 0.0 & 1.0 & 0.0 & 0.0 & 0.2 & 0.0 \\
\hline F7 & 3.0 & 2.0 & 2.0 & 2.0 & 2.0 & 3.0 & 0.0 & 1.0 & 1.0 \\
\hline F8 & 3.0 & 0.0 & 1.0 & 2.0 & 1.0 & 1.0 & 1.0 & 0.0 & 1.0 \\
\hline F9 & 2.0 & 2.0 & 0.5 & 1.0 & 2.0 & 0.5 & 1.0 & 0.5 & 0.0 \\
\hline
\end{tabular}

Source: Authors' own work

Table 2: T Matrix, and ' $R+C$ ' \& ' $R-C$ ' for Factors of Health

\begin{tabular}{lcccccccccccccccc}
\hline & F1 & F2 & F3 & F4 & F5 & F6 & F7 & F8 & F9 & r & c & r+c & r-c \\
\hline F1 & 0.05 & 0.03 & 0.18 & 0.01 & 0.08 & 0.03 & 0.07 & 0.02 & 0.02 & 0.50 & 1.90 & 2.41 & -1.40 \\
F2 & 0.23 & 0.05 & 0.27 & 0.02 & 0.11 & 0.08 & 0.06 & 0.05 & 0.03 & 0.91 & 1.12 & 2.04 & -0.21 \\
F3 & 0.21 & 0.13 & 0.08 & 0.02 & 0.14 & 0.07 & 0.04 & 0.05 & 0.03 & 0.78 & 1.75 & 2.52 & -0.97 \\
F4 & 0.31 & 0.24 & 0.34 & 0.02 & 0.10 & 0.25 & 0.07 & 0.05 & 0.13 & 1.51 & 0.51 & 2.02 & 1.00 \\
F5 & 0.14 & 0.08 & 0.15 & 0.10 & 0.08 & 0.07 & 0.19 & 0.18 & 0.19 & 1.19 & 1.04 & 2.22 & 0.15 \\
F6 & 0.22 & 0.18 & 0.19 & 0.01 & 0.10 & 0.03 & 0.03 & 0.04 & 0.02 & 0.82 & 0.92 & 1.74 & -0.10 \\
F7 & 0.30 & 0.19 & 0.25 & 0.13 & 0.18 & 0.21 & 0.06 & 0.10 & 0.10 & 1.53 & 0.70 & 2.24 & 0.83 \\
F8 & 0.24 & 0.07 & 0.15 & 0.12 & 0.10 & 0.10 & 0.09 & 0.03 & 0.08 & 0.99 & 0.59 & 1.58 & 0.40 \\
F9 & 0.19 & 0.15 & 0.13 & 0.07 & 0.15 & 0.07 & 0.09 & 0.06 & 0.04 & 0.95 & 0.64 & 1.59 & 0.31 \\
\hline
\end{tabular}

Source: Authors' own work 
Table 3: T Matrix, and ' $\mathrm{R}+\mathrm{C}$ ' \& 'R-C' for Factors of $\mathrm{PH}$

\begin{tabular}{|c|c|c|c|c|c|c|c|c|c|c|}
\hline & F1 & F2 & F3 & F4 & F5 & F6 & $r$ & c & $r+c$ & $r-c$ \\
\hline F1 & 0.07 & 0.04 & 0.26 & 0.01 & 0.12 & 0.02 & 0.52 & 1.64 & 2.16 & -1.12 \\
\hline $\mathrm{F} 2$ & 0.35 & 0.09 & 0.42 & 0.01 & 0.17 & 0.11 & 1.14 & 1.00 & 2.15 & 0.14 \\
\hline F3 & 0.31 & 0.19 & 0.15 & 0.01 & 0.21 & 0.10 & 0.98 & 1.83 & 2.81 & -0.85 \\
\hline F4 & 0.49 & 0.37 & 0.56 & 0.01 & 0.17 & 0.36 & 1.97 & 0.13 & 2.10 & 1.84 \\
\hline F5 & 0.06 & 0.04 & 0.12 & 0.07 & 0.03 & 0.03 & 0.35 & 0.86 & 1.21 & -0.50 \\
\hline F6 & 0.35 & 0.27 & 0.32 & 0.01 & 0.16 & 0.05 & 1.16 & 0.67 & 1.83 & 0.50 \\
\hline
\end{tabular}

Source: Authors' own work

Table 4: T Matrix, and ' $r+c$ ' \& ' $r$-c' for Factors of $\mathrm{MH}$

\begin{tabular}{|c|c|c|c|c|c|c|c|c|c|c|}
\hline & F4 & F5 & F6 & F7 & F8 & F9 & $r$ & c & $r+c$ & $r-c$ \\
\hline F4 & 0.03 & 0.06 & 0.32 & 0.06 & 0.04 & 0.17 & 0.68 & 0.73 & 1.41 & -0.05 \\
\hline F5 & 0.18 & 0.11 & 0.14 & 0.29 & 0.27 & 0.30 & 1.31 & 0.77 & 2.08 & 0.54 \\
\hline F6 & 0.02 & 0.08 & 0.01 & 0.02 & 0.03 & 0.02 & 0.19 & 1.04 & 1.23 & -0.85 \\
\hline F7 & 0.20 & 0.21 & 0.30 & 0.07 & 0.13 & 0.16 & 1.07 & 0.69 & 1.76 & 0.38 \\
\hline F8 & 0.18 & 0.12 & 0.16 & 0.12 & 0.04 & 0.14 & 0.76 & 0.62 & 1.38 & 0.14 \\
\hline F9 & 0.12 & 0.19 & 0.11 & 0.13 & 0.09 & 0.07 & 0.70 & 0.86 & 1.57 & -0.16 \\
\hline
\end{tabular}

Source: Authors' own work
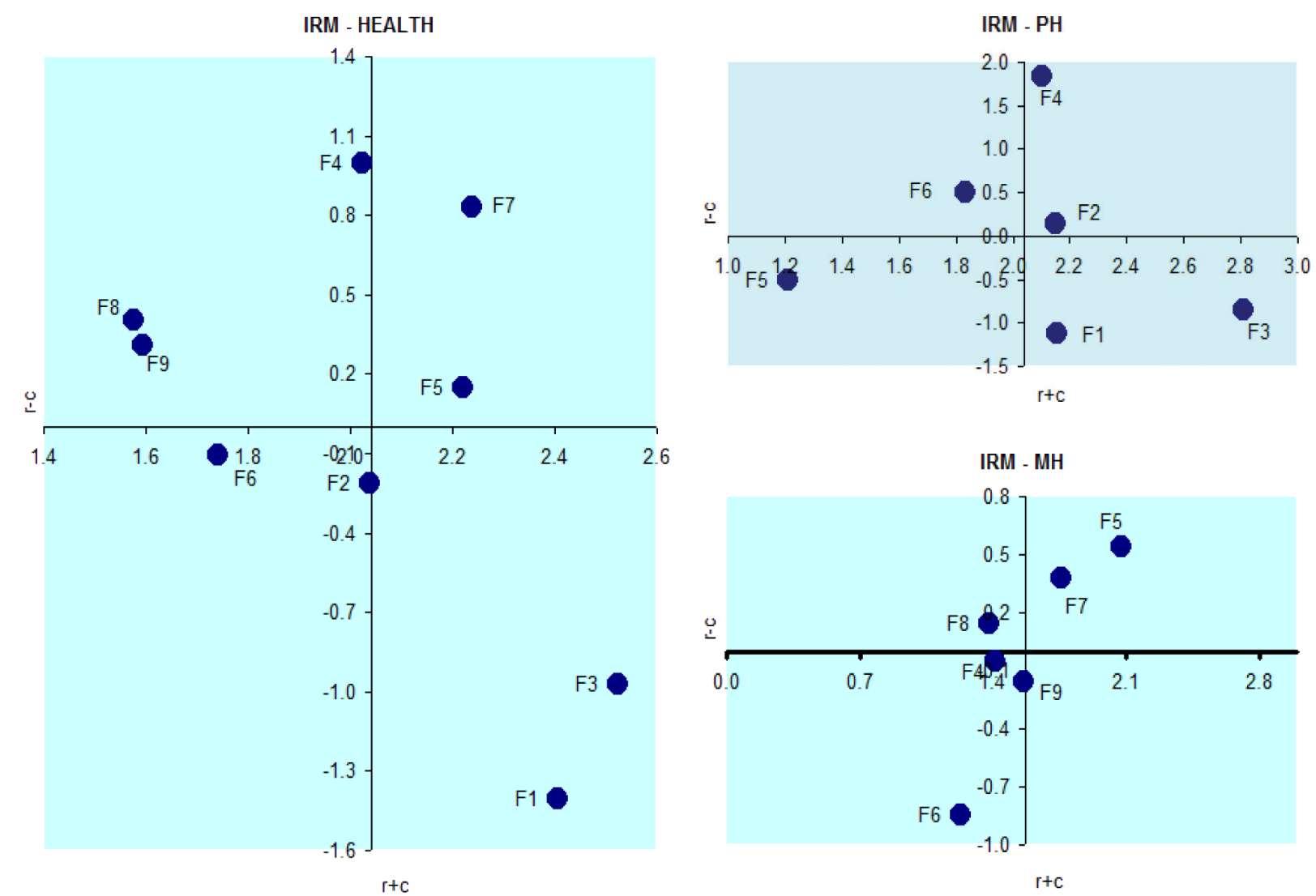

Figure 3: IRMs for factors of health, $\mathrm{PH}$ and $\mathrm{MH}$ Source: Authors' own work 
Table 5: Barriers for SSCM

\begin{tabular}{|c|c|c|}
\hline “Category" & Barrier (identification code) & Critical? \\
\hline \multirow[t]{4}{*}{ "Environment" } & "Lack of eco-literacy amongst supply chain partner (E1)" & Yes \\
\hline & "Lack of environmental requirement (E2)" & \\
\hline & "Lack of practice on reverse logistics (E3)" & \\
\hline & "Lack of awareness of local customers in green product (E4)" & Yes \\
\hline \multirow[t]{4}{*}{ "Technology" } & "Lack of technical expertise (T1)" & \\
\hline & "Resistance to change and adopt innovation (T2)" & \\
\hline & "Lack of cleaner technology (T3)" & Yes \\
\hline & "Outdated machineries (T4)" & \\
\hline \multirow[t]{4}{*}{ "Knowledge \& Support" } & “Information gap (KS1)" & Yes \\
\hline & "Lack of commitment from top management (KS2)" & Yes \\
\hline & "Lack of training and education about sustainability (KS3)" & \\
\hline & "Limited access to market information (KS4)" & Yes \\
\hline \multirow[t]{4}{*}{ "Society" } & "Lack of government support \& guideline to adopt sustainable supply chain practices (S1)" & Yes \\
\hline & "Absence of society pressure (S2)" & Yes \\
\hline & "Lack demand \& pressure for lower price (S3)" & \\
\hline & "Less of business friendly policy (S4)" & \\
\hline \multirow[t]{4}{*}{ "Financial" } & "Cost of sustainability \& economic condition (F1)" & Yes \\
\hline & "Capacity constraints (F2)" & \\
\hline & "Lack of funds for sustainable supply chain practices (F3)" & \\
\hline & “Green power shortage (F4)” & \\
\hline
\end{tabular}

Source: Moktadir et al., 2018

objective and then combined for a complete real set of critical factors.

This result can also be justified from previous researches. For example, researchers Moktadir et al. (2018) classified 20 "common barriers with the help of experts and academic feedback" out of their primary list of 35 barriers for "Sustainable Supply Chain Management" (SSCM) and then using DEMATEL, found nine critical barriers as given below:

Surprisingly, "Lack of funds for sustainable supply chain practices (F3)" did not come out as critical, especially, for a country like Bangladesh, a poor (Sultana \& Mallick, 2015), and the most densely populated (Islam, 2009) country in the world where most of the people basically depend on cheaper commodity! In general, if there is a lack of funds to take initiative to implement, there is no point in considering "Lack of eco-literacy amongst supply chain partner (E1)", "Lack of cleaner technology (T3)" as critical; they all become secondary. If financial issues are not resolved, it may not matter whether access to market information is abundant or not. In this situation of fund crisis, people may not get training continuously and/or even trained people can not apply their skills and knowledge. First gap in this analysis is categorization which is not based on distinct unit level. Hence the same weight of all parallel factors influenced the method incorrectly and moved towards misleading decisions.

Again, "Lack of commitment from top management (KS2)" may be the major reason for "Lack of funds for sustainable supply chain practices (F3)". But if the shareholders' expectations are not addressed in the policy for sustainable development, top management commitment for sustainability may be treated as emotions only, not a practical idea of concerns with the sacrifice of primary profits. "Information gap (KS1)", another critical factor under" the category of "Knowledge \& Support" may also remain less influential.

"Cost of sustainability \& economic condition (F1)" and "Lack of government support \& guideline to adopt sustainable supply chain practices (S1)" may not be in control of organization implementing SSCM. These critical factors need to be clarified that they are considered from the organization or government point of view; in both cases, one of those will remain considerable and the other is not. Moreover, simultaneously, both "Lack of government support \& guideline to adopt sustainable supply chain practices (S1)" and "Absence of society pressure ( $\mathrm{S} 2$ )" have been identified as critical which 
basically have relation to social sustainability. But if there is enough societal pressure, government will support unavoidably (Scott, 1998). So, only S2 is critical. Again, among the other factors under this category, if DEMATEL was applied separately within this category only, in addition to "Absence of society pressure (S2)", "Lack demand \& pressure for lower price (S3)" might also appear as critical as it has a high impact on investors' decisions (Hendershott \& Menkveld, 2014).

Also, the grouping of factors needs to be effective. Each group should be an integral part of the system. Again, the same system like customer relationship management (CRM) system in different kind of organizations like bank, hotel, library, etc. has different factors requiring to be grouped in different ways. Wrong grouping may bring misleading results. For example, to identify possible relations among factors measuring CRM performance from the management point of view and to determine key factors for successful CRM strategy for the company, Pechová (2015) conducted a research based on the application of the DEMATEL method within the CRM Scorecard model. The researcher divided factors influencing CRM performance and factors influencing successful CRM system implementation into "four groups:

- Infrastructure perspective - IT (CRM technology), human capital (employee behaviour, employee satisfaction, management attitude), organizational alignment (training, reward system, organizational structure), culture (partnership, market orientation, explicit goal),

- Process perspective - customer acquisition, customer retention, customer expansion,

- Customer perspective - customer loyalty, customer satisfaction, customer value,

- Organizational performance perspective - shareholder value, profitability, customer equity".

Every group of factors was compared among the other groups and also every factor within the group was compared to related factors. The most affecting group of factors was the infrastructure, followed by process perspective; and management attitude, customer acquisition, customer loyalty and customer equity appeared as the most influencing factors in their respective group (Pechová, 2015). Due to wrong or generic categorization, the results were not trustworthy enough.

"Main success factors of CRM implementation based on a sample of 128 small- and medium-sized hotels in Spain" were found organisational factors: "top management support, employee training and motivation along with organisational structure/processes" (Padilla-Meléndez \& Garrido-Moreno, 2014). "The knowledge and understanding of CRM of library staff and leadership of library administrators which include the perception and awareness of service quality focusing on customer relationship" were found as the most significant factors for CRM practices in Thai academic libraries. "Important factors also include the acceptance and support of the use of CRM in the library, the clear vision and mission about using CRM in the library strategic plan, the knowledge and understanding of library staff on CRM processes, customer characteristics, and behaviors" (Siriprasoetsin et el., 2011).

\section{Conclusion}

DEMATEL is sensitive to data uncertainty. If "combined grey-based DEMATEL" (Moktadir et al., 2018) is used, such uncertainty is overcome. But to take correct decisions, the DEMATEL analysis must be used for clusters of distinct components or elements effectively grouped for any system to merge all critical factors and merge them to avoid any factors lost in overall competition. Some factors may not be in the higher rank in overall implementation but for a specific element of a specific element they can be highly influential. The results may vary in higher amount when bigger number of any data (factors and elements) is in use. In that case, appropriate weights for elements may reduce the variation in results but still the elemental approach remains as the only correct way.

\section{References}

Agi, M. A., \& Nishant, R. (2017). Understanding influential factors on implementing green supply chain management practices: An interpretive structural modelling analysis. Journal of environmental management, 188, 351-363.

Bai, C., \& Sarkis, J. (2013). A grey-based DEMATEL model for evaluating business process management critical success factors. International Journal of Production Economics, 146(1), 281-292.

Bagozzi, R. P. (2010). Structural equation models are modelling tools with many ambiguities: Comments acknowledging the need for caution and humility in their use. Journal of Consumer Psychology, 20(2), 208-214.

Berk, R. A., \& Freedman, D. A. (2003). Statistical assumptions as empirical commitments. Law, punishment, and social control: Essays in honor of Sheldon Messinger, 2, 235-254.

Bouzon, M., Govindan, K., \& Rodriguez, C. M. T. (2018). Evaluating barriers for reverse logistics implementation under a multiple stakeholders' perspective analysis using 
grey decision making approach. Resources, Conservation and Recycling, 128, 315-335.

Dong, S., Tian, L., \& Li, R. (2016). Critical factors of sustainable innovation capability identify method based on fuzzy theory and dematel. 2016 International Conference on Machine Learning and Cybernetics (ICMLC). doi:10.1109/ icmlc.2016.7872988.

Ferreira, F. A., Ferreira, J. J., Fernandes, C. I., MeidutèKavaliauskienè, I., \& Jalali, M. S. (2017). Enhancing knowledge and strategic planning of bank customer loyalty using fuzzy cognitive maps. Technological and Economic Development of Economy, 23(6), 860-876.

Gabus, A., \& Fontela, E. (1973). Perceptions of the world problematique: Communication procedure, communicating with those bearing collective responsibility. DEMATEL 1. Battelle Geneva Research Centre, Geneva.

Gan, J., \& Luo, L. (2017). Using DEMATEL and intuitionistic fuzzy sets to identify critical factors influencing the recycling rate of end-of-life vehicles in China. Sustainability. 9(10), 1873.

Girubha, J., Vinodh, S., \& Kek, V. (2016). Application of interpretative structural modelling integrated multi criteria decision making methods for sustainable supplier selection. Journal of Modelling in Management, 11(2), 358-388.

Gołąbeska, E. (2018). The Dematel Method in the Analysis of the Residential Real Estate Market in Bialystok. Real Estate Management and Valuation, 26(1), 16-25.

Gölcük, İ., \& Baykasoğlu, A. (2016). An analysis of DEMATEL approaches for criteria interaction handling within ANP. Expert Systems with Applications, 46, 346-366.

Hair, J. F., Sarstedt, M., Ringle, C. M., \& Mena, J. A. (2012). An assessment of the use of partial least squares structural equation modeling in marketing research. Journal of the academy of marketing science, 40(3), 414-433.

Hendershott, T., \& Menkveld, A. J. (2014). Price pressures. Journal of Financial Economics, 114(3), 405-423.

Islam, M. B. (2009). Blood transfusion services in Bangladesh. Asian journal of transfusion science, 3(2), 108. doi:10.4103/0973-6247.53880

Köksalan, M., Wallenius, J., \& Zionts, S. (2011). Multiple Criteria Decision Making: From Early History to the 21st Century. Toh Tuck Link, Singapore: World Scientific.

Kusi-Sarpong, S., Sarkis, J., \& Wang, X. (2016). Assessing green supply chain practices in the Ghanaian mining industry: A framework and evaluation. International Journal of Production Economics, 181, 325-341.

Liou, J. J., \& Tzeng, G. H. (2012). Comments on "Multiple criteria decision making (MCDM) methods in economics: an overview". Technological and Economic Development of Economy, 18(4), 672-695.

Liou, J. J. H., Tzeng, G. H. \& Chang, H. C. (2007). Airline safety measurement using a novel hybrid model. Journal of Air Transport Management, 13(4), 243-249.
Liu, C. C., Li, L., \& Gao, Y. (2011). Analysis of the relationship between the influential factors of regional FEEEP coordinated growth based on the DEMATEL method. In Applied Mechanics and Materials (Vol. 71, pp. 2210-2213). StafaZurich, Switzerland: Trans Tech Publications.

Mangla, S. K., Luthra, S., Rich, N., Kumar, D., Rana, N. P., \& Dwivedi, Y. K. (2018). Enablers to implement sustainable initiatives in agri-food supply chains. International Journal of Production Economics, 203, 379-393.

Marvin, H. J., Bouzembrak, Y., Janssen, E. M., van der Zande, M., Murphy, F., Sheehan, B., ... \& Bouwmeester, H. (2017). Application of Bayesian networks for hazard ranking of nanomaterials to support human health risk assessment. Nanotoxicology, 11(1), 123-133.

Moktadir, M. A., Ali, S. M., Rajesh, R., \& Paul, S. K. (2018). Modeling the interrelationships among barriers to sustainable supply chain management in leather industry. Journal of Cleaner Production, 181, 631-651. doi:10.1016/j. jclepro.2018.01.245.

Omrani, H., Valipour, M., \& Emrouznejad, A. (2019). Using weighted goal programming model for planning regional sustainable development to optimal workforce allocation: an application for provinces of Iran. Social Indicators Research, 141(3), 1007-1035.

Patil, S. K., \& Kant, R. (2013). A fuzzy DEMATEL method to identify critical success factors of knowledge management adoption in supply chain. Journal of Information \& Knowledge Management, 12(3), 1350019.

Padilla-Meléndez, A., \& Garrido-Moreno, A. (2014). Customer relationship management in hotels: examining critical success factors. Current issues in tourism, 17(5), 387-396.

Pechová, H. (2015). Application of DEMATEL Method in CRM Performance Measurement. In Conference Proceedings of MEKON 2015 Selected Papers.

Purohit, J. K., Mittal, M. L., Mittal, S., \& Sharma, M. K. (2016). Interpretive structural modeling-based framework for mass customisation enablers: An Indian footwear case. Production Planning \& Control, 27(9), 774-786.

Rodrigues, T. C., Montibeller, G., Oliveira, M. D., \& e Costa, C. A. B. (2017). Modelling multicriteria value interactions with Reasoning Maps. European Journal of Operational Research, 258(3), 1054-1071.

Salmeron, J. L., Vidal, R., \& Mena, A. (2012). Ranking fuzzy cognitive map based scenarios with TOPSIS. Expert Systems with Applications, 39(3), 2443-2450.

Scott, H. (1998, June 12). Social Pressure as a Moral \& Political Tool. Retrieved from http://www.massline.org/Philosophy/ ScottH/social_pressure.htm

Shieh, J. I., Wu, H. H., \& Huang, K. K. (2010). A DEMATEL method in identifying key success factors of hospital service quality. Knowledge-Based Systems, 23(3), 277-282.

Siriprasoetsin, P., Tuamsuk, K., \& Vongprasert, C. (2011). Factors affecting customer relationship management practices in 
Thai academic libraries. The international information \& library review, 43(4), 221-229.

Si, S. L., You, X. Y., Liu, H. C., \& Zhang, P. (2018). DEMATEL technique: A systematic review of the state-of-the-art literature on methodologies and applications. Mathematical Problems in Engineering, 2018.

Sivakumar, K., Jeyapaul, R., Vimal, K. E. K., \& Ravi, P. (2018). A DEMATEL approach for evaluating barriers for sustainable end-of-life practices. Journal Of Manufacturing Technology Management, 29(6), 1065-1091.

Spronk, J., Steuer, R. E., \& Zopounidis, C. (2005). Multicriteria decision aid/analysis in finance. In Multiple criteria decision analysis: State of the art surveys (pp. 799-848). New York, NY; Springer.

Sultana, Z., \& Mallick, B. (2015). Adaptation strategies after cyclone in southwest coastal Bangladesh-pro poor policy choices. American Journal of Rural Development, 3(2), 24-33.

Sumrit, D., \& Anuntavoranich, P. (2013). Using DEMATEL method to analyze the causal relations on technological innovation capability evaluation factors in Thai technology-based firms. International Transaction Journal of Engineering, Management, \& Applied Sciences \& Technologies, 4(2), 81-103.

Tzeng, G., \& Shen, K. (2017). New Concepts and Trends of Hybrid Multiple Criteria Decision Making. Boca Raton, FL: CRC Press.

Tzeng, G. H., Chiang, C. H. \& Li, C. W. (2007). Evaluating intertwined effects in e-learning programs: a novel hybrid MCDM model based on factor analysis and DEMATEL. Expert Systems with Applications, 32(4), 1028-1044.
Wu, W. W. \& Lee, Y. T. (2007). Developing global managers' competencies using the fuzzy DEMATEL method. Expert Systems with Applications, 32(2), 499-507.

Wu, K. J., Liao, C. J., Tseng, M. L., \& Chiu, A. S. (2015). Exploring decisive factors in green supply chain practices under uncertainty. International Journal of Production Economics, 159, 147-157.

Wu, H., \& Chang, S. (2015). A case study of using DEMATEL method to identify critical factors in green supply chain management. Applied Mathematics and Computation, 256, 394-403. doi:10.1016/j.amc.2015.01.041.

Xu, Z., \& Coors, V. (2012). Combining system dynamics model, GIS and 3D visualization in sustainability assessment of urban residential development. Building and Environment, $47,272-287$.

Yang, Y., \& John, R. (2003, September). Grey systems and interval valued fuzzy sets. In EUSFLAT Conf. (pp. 193-197).

Yang, Y. P., Shieh, H. M., Leu, J. D. and Tzeng, G. H. (2008). A novel hybrid MCDM model combined with DEMATEL and ANP with applications. International Journal Operational Research, 5(3), 160-168.

Yu, R. \& Tseng, G. H. (2006). A soft computing method for multi-criteria decision making with dependence and feedback. Applied Mathematics Computation, 180(1), 63-75.

Zeng, Z., Jiang, X., \& Neapolitan, R. (2016). Discovering causal interactions using Bayesian network scoring and information gain. BMC bioinformatics, 17(1), 221.

Zhu, Q., Sarkis, J., \& Geng, Y. (2011). Barriers to environmentally-friendly clothing production among Chinese apparel companies. Asian Business \& Management, 10(3), 425-452. 